\title{
Surgeons swear when operating: fact or myth?
}

\author{
F Fausto Palazzo, Orlando J Warner
}

The medical profession is rich with anecdotes about surgeons, many of national and international repute, using colourful language in the operating theatre. Legend has it that the language of the mildest mannered and pious surgeon, once he or she is gowned and gloved, undergoes a transformation. However, a Medline search of the past 20 years using the search words "swear," "swearing," "foul language," and "blasphemy" produced no relevant articles on the subject.

We therefore assessed to what extent the use of foul language by surgeons is a myth. We also tried to identify the surgical specialties where swearing is most common.

\section{Materials, methods, and results}

One hundred consecutive elective operations under general anaesthesia performed at a single hospital were assessed for the incidence of swearing by the operating surgeon. Without the surgeon's knowledge a swearing score was kept during surgery. The scoring was always undertaken by the same person (OJW). Other data recorded comprised the specialty of the surgeon, the length of the operation, and the type of foul language used. The swear words were classified into three groups, with points assigned to each swear word to reflect its strength: heaven and hell (such as "God," "bloody hell," "bugger"), 1 point; bodily products (such as "sh*t," "p*ss"), 2 points; so called four letter words (such as "f***," "c****," "b***ard") 3 points.

For strings of swear words, the highest scoring obscenity alone was counted. To guarantee the anonymity of surgeons, no distinction was made between their grade and sex. The swear rate was calculated from the total operating time and total scores for each specialty.

The 100 operations from five surgical specialties totalled 80 hours 30 minutes' operating time. Ninety four swearing points were scored, with an average of one point scored every 51.4 minutes. Different surgical specialties had different swearing rates (figure). Rates for a typical eight hour operating day were 16.5 swearing points from the orthopaedic surgeons and 10.6, 10, and 3.1 from the general surgeons, gynaecologists, and urologists respectively. In contrast, during eight hours of ear, nose, and throat surgery, little more than one "bugger!" is likely (figure).

\section{Comment}

Surgeons do swear when operating but the rate differs by specialty. Orthopaedic surgeons on average register one swear point every 29 minutes, almost twice as often as surgeons overall. Although orthopaedic surgeons triumph in the field of foul language, general surgeons are by no means without sin, being only slightly less foul mouthed than their orthopaedic colleagues. Gynaecologists also seem anything but angelic but may have been penalised by a small sample size of operating time. The 95\% confidence interval shows that gynaecologists may actually use more foul

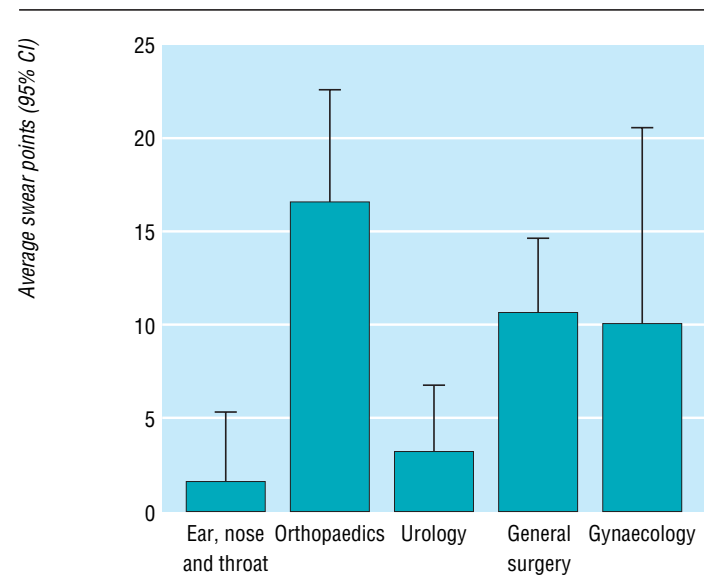

Department of Immunology, St Bartholomew's and Royal London Hospitals Medical School, London EC1A 7BE

F Fausto Palazzo surgical research fellow

Anaesthetics, Oxford Deanery, 20 East Street, Oxford OX2 OAU Orlando J Warner specialist registrar

Correspondence to: F F Palazzo F.F.Palazzo@ qmw.mds.ac.uk

$\begin{array}{rccccc}\text { No of operations } & 19 & 23 & 20 & 29 & 9 \\ \text { Operating time (mins) } & 655 & 1190 & 935 & 1715 & 335 \\ \text { Swearing points } & 2 & 41 & 6 & 38 & 7 \\ \text { Operating mins/points } & 328 & 29 & 156 & 45 & 48 \\ \text { Points/8h (95\% } & 1.5(0.1 & 16.5(11.8 & 3.1(1.1 & 10.6(7.5 & 10(4 \\ \text { confidence interval) } & \text { to } 5.3) & \text { to 22.4) } & \text { to } 6.7) & \text { to 14.6) } & \text { to 20.6) }\end{array}$

BMJ 1999;319:1611

Rates of swearing during 100 operations, by specialty

language than general surgeons. Meanwhile the mild mannered ear, nose, and throat surgeons contribute little, with nearly five hours of operating time on average without any obscenity.

The reasons for the differential swearing pattern is difficult to establish. The brevity of the operations in some specialties may be a determinant. The orthopaedic operations lasted an average of 51.7 minutes, compared with 34.4 minutes per ear, nose, and throat operation. However, the average gynaecological procedure lasted just 37.2 minutes-during which time there was nevertheless a good chance of hearing an expletive. Does the use of complicated orthopaedic tools encourage bad language in the theatre? Does the good or bad language of a surgeon lead to a greater or lesser chance of career progression, depending on the specialty? Unanswered questions for the next millennium.

Given that the operations were elective, this may be the tip of the iceberg as even more foul language might occur in out of hours operating. However, the increasing practice of routine surgery under local and regional anaesthesia may already be enforcing some restraint of the surgical tongue. Is perhaps 1 January 2000 a good time for surgeons to resolve to stop swearing in theatre, or should we not surrender one of the last bastions of surgical tradition and privilege?

We thank the surgeons of the Royal Berkshire Hospital, Reading, for their good natured participation in this study.

Contributors: Both authors collaborated in the design of the study. The data were collected by OJW and analysed by FFP. The paper was written by FFP and revised by OJW. Both authors will act as guarantors.

Funding: None.

Competing interests: None declared. 